\title{
Study on Landscape Pattern Based on Landsat-8 in the Center of Chengdu City, China
}

\author{
Wei He ${ }^{1 *}$, Youyou Huang2,3*\#, Xin Dong1, Xianchun Yan', Dengfei Li ${ }^{1}$ \\ ${ }^{1}$ College of Life Science, China West Normal University, Nanchong, China \\ ${ }^{2}$ Key Laboratory of Southwest China Wildlife Resources Conservation, China West Normal University, Ministry \\ of Education, Nanchong, China \\ ${ }^{3}$ State Key Laboratory of Geoenvironment Protection, Chengdu University of Technology, Chengdu, China \\ Email: \#yhuang_cwnu@163.com
}

Received 15 May 2016; accepted 13 June 2016; published 16 June 2016

Copyright (C 2016 by authors and Scientific Research Publishing Inc.

This work is licensed under the Creative Commons Attribution International License (CC BY). http://creativecommons.org/licenses/by/4.0/

(c) (i) Open Access

\section{Abstract}

Study on landscape spatial pattern in the center of Chengdu City is based on the Landsat-8 image by using $3 S$ technique and spatial pattern analysis software Fragstats 3.3. The results showed that there covered an area of $193.92 \mathrm{~km}^{2}$ in the center of Chengdu City. $55.24 \%$ of the total area was made up of buildings, covering an area of $107.12 \mathrm{~km}^{2}$, and the overall landscape of impervious ground-based. There were 22,666 patches; $29.67 \%$ of the patches were roads. The human interference of buildings, roads and green space was a maximum; fragmentation of the highest was green space. The fragmentation of overall urban landscape was high; the diversity was low; the value of Shannon's diversity index was 0.63; the value of Shannon's evenness index was 0.70. All kinds of landscape distribution were not balanced, and lack of connectivity. This research puts important reference for creating good urban landscape space and restoring the natural ecological environment in the western regions of China.

\section{Keywords}

Chengdu City, Landscape Pattern, Urban Landscape, 3S Technique, Landscape Index

\section{Preface}

It is reported that the country's urbanization rate rose from $17.9 \%$ to $56.1 \%$ from 1978 to 2015 [1], and it will ${ }^{*}$ These authors contributed equally to this study and share first authorship.

\#Corresponding author.

How to cite this paper: He, W., Huang, Y.Y., Dong, X., Yan, X.C. and Li, D.F. (2016) Study on Landscape Pattern Based on Landsat-8 in the Center of Chengdu City, China. Journal of Environmental Protection, 7, 1050-1056.

http://dx.doi.org/10.4236/jep.2016.77093 
reach $72.9 \%$ by 2050 . With the population increase and expanding the number and scale of city, urban natural and semi-natural underlying surfaces were gradually replaced by impervious surfaces; artificial elements were replaced by natural elements; these become the basic features of urban landscape change in recent decades of worldwide. At the same time, more and more cities are facing environmental pollution, resource shortages, traffic congestion and other ecological problems, which are closely related to human disturbance of the change of urban landscape pattern [2]. By analyzing the spatial structure of urban landscape, it can reflect the human activities and environmental interference in a certain social forms [2] and it is of great significance to optimize the urban space and solve the problems of the urban ecological environment.

The successful launch of the Landsat-8 satellite provides more reliable date image than the Landsat-7 and Landsat 4-5 series for resources, water, forests, environment and urban planning [3]. At the same time, the efficient development of remote sensing and geographic information system technology provides more accurate technical support for the quantitative analysis of urban landscape pattern. In Chengdu, one of the major cities of the development of urbanization in West China [4], great changes have occurred in the landscape pattern with the development of urbanization. Based on the SPOT and Landsat-7 data, Gao, S. P. [5], Chen, H., [6] and He, X. L. [4] made a quantitative and qualitative analysis about the landscape composition of Chengdu. For Chengdu City, Chen, W. J. [7] and Ou, D. H. [8] provided a preliminary study of the data process by using Landsat-8. However, the study of urban landscape in the region was more concentrated in the use of early remote sensing data for rough extraction, or to initial treatment for Landsat-8 data. In this paper, the quantitative analysis of the landscape spatial pattern in the center of Chengdu City was carried out by using the latest Landsat-8 remote sensing data and $3 \mathrm{~S}$ general treatment technology. In order to effectively reflect the current situation of the landscape pattern of Chengdu, it is better to understand the interaction between urbanization and landscape elements, and to provide scientific basis and theoretical support for the regional urban planning.

\section{Research Area Survey}

Chengdu is located in the central part of Sichuan province and the western part of Sichuan basin. It is the center of political, economy and culture in Southwest China. Chengdu is located in the subtropical area, within an average elevation of $500 \mathrm{~m}$, annual average temperature of $16.5 \%$, the average annual rainfall of $982.4 \mathrm{~mm}$, with warm in winter and early spring and four distinct seasons [6] [8]. Chengdu has rich biological resources and a long history and culture. The research area is the area within the third-ring road of Chengdu. It is the highest city level of Chengdu and the most perfect development area. The study of urban landscape pattern in this area is of great significance to improve the quality of residents' living environment and to realize the urban landscape structure.

\section{Materials and Methods}

\subsection{Data Sources and Processing}

In this paper, based on the spatial resolution of $30 \mathrm{~m}$ of Landsat-8 image date of Chengdu on August 13, 2014, the track number is p129r39, the value of cloud is 3.74, and some auxiliary data, for instance, 1:50,000 terrain data, planning map, topographic map, administrative thematic map data, the field survey data of Chengdu, etc. With the technology platform of ArcGIS, ENVI and ERDAS, for better distinguish urban water and vegetation information, used the combination of 764 band (Figure 1), and used the combination of ISODATA non supervised classification and visual interpretation to divide the types of landscape, according to the ENVI software contingency matrix of evaluate classification signature to got the classification accuracy of 6 types, the accuracy were $94.39 \%$, 96.76\%, 94.77\%, 97.80\%, 97.08\% and 93.94\% respectively, and the overall classification accuracy has reached $95.79 \%$ (Table 1 ).

\subsection{Landscape Classification and Selection of Urban Landscape Index}

In view of the surface display characteristic of Chengdu, and reference the classification criteria of Beijing by Yang, W. R. [9] and the classification criteria about urban green space landscape pattern analysis of Chengdu by He, X. L. [4]. The landscape in the center of Chengdu City was divided into 6 types, including green space, buildings, roads, cultivated land, water and other.

Under the support of Fragstats 3.3 software, selected 13 indexes at the type level, including class area (CA), 


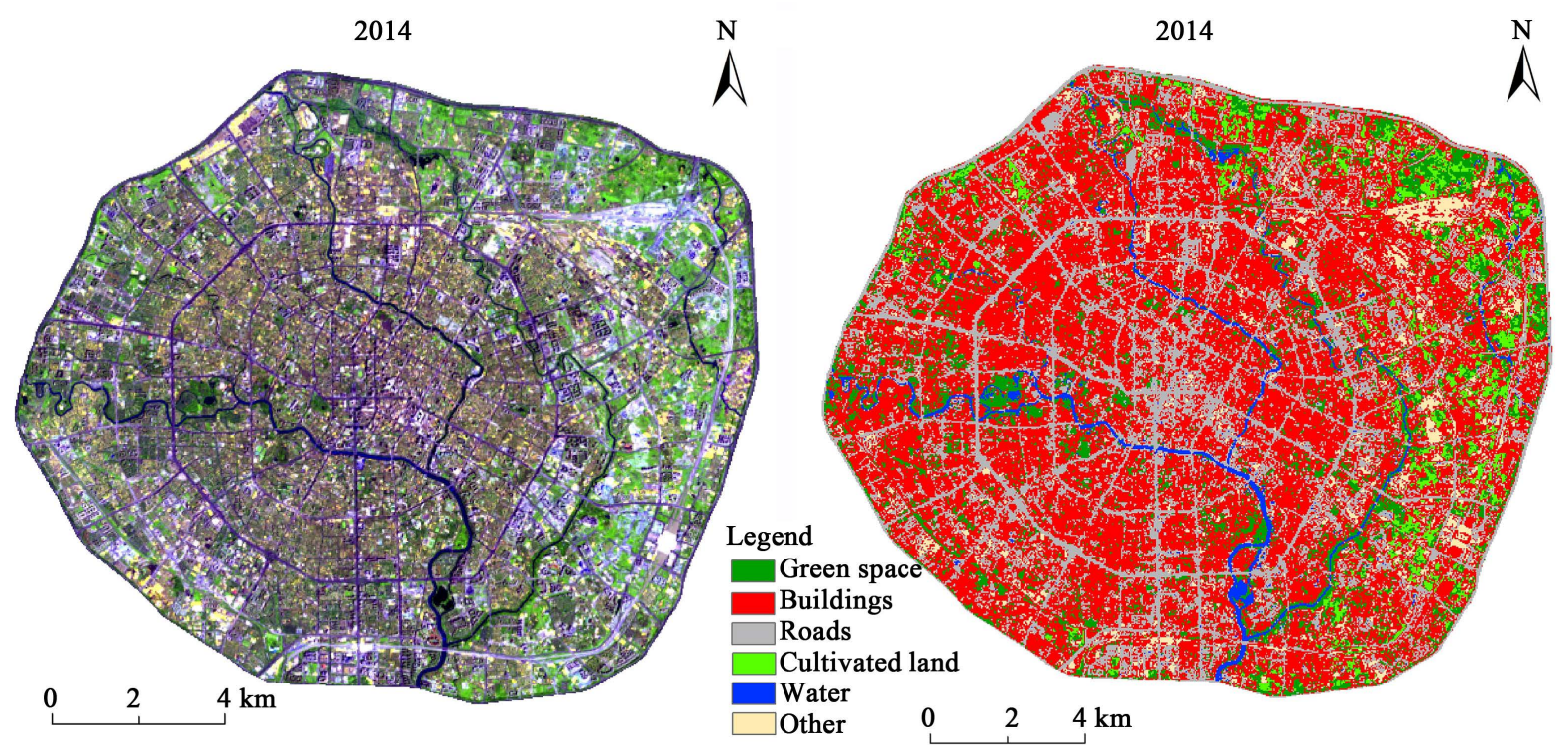

Figure 1. 764 band combination images and the structure map of landscape class in the center of Chengdu city.

Table 1. The contingency matrix of evaluate classification signature.

\begin{tabular}{cccccccc}
\hline Type & Green space & Buildings & Roads & Cultivated land & Water & Other & Sum \\
\hline Green space & 101 & 1 & 0 & 1 & 1 & 0 & 104 \\
Buildings & 3 & 179 & 4 & 1 & 0 & 4 & 191 \\
Roads & 2 & 5 & 163 & 0 & 3 & 0 & 173 \\
Cultivated land & 0 & 0 & 0 & 09 & 133 & 0 & 139 \\
Water & 1 & 0 & 5 & 0 & 137 & 62 & 62 \\
Other & 0 & 0 & 0 & 91 & 97.08 & 93.94 & 95.79 \\
Sum & 107 & 185 & 172 & 97.80 & & 0 & 758 \\
Accuracy (\%) & 94.39 & 96.76 & 94.77 & & & 0 \\
\hline
\end{tabular}

Number of Patches (NP), Landscape Shape Index (LSI) and Mean Shape Index (MSI), Mean Patch Fractal Dimension (MPFD), Area-Weighted Mean Shape Index (AWMSI), Area-Weighted Mean Patch Fractal Dimension (AWMPFD), Patch Density (PD), Edge Density (ED), Mean Patch Size (MPS), Fragmentation (FN) [10], Aggregation Index (AI) and Interspersion and Juxtaposition Index (IJI), and 6 indexes at the landscape level, including Patch Density (PD), Mean Patch Fractal Dimension (MPFD), Aggregation Index (AI), Shannon’s Diversity Index (SHDI), Shannon’s Evenness Index (SHEI), Contagion Index (CONTAG).

\section{Results and Analysis}

\subsection{Analysis and Selection of Urban Landscape Pattern Index}

Table 2 showed that there were covering an area of $193.92 \mathrm{~km}^{2}$ in the center of Chengdu City, the area and the largest proportion of the landscape type was buildings (55.24\%), followed by roads (23.27\%), buildings constitute the bottom of the whole study area. There were 22,666 patches, of which the largest proportion of landscape type was roads (29.67\%), followed by green space (24.92\%) and buildings $(23.00 \%)$. On distribution of landscape types, the main city area was mainly covered with buildings and roads. Green space was distributed sporadic; the types of attached green space and parks were common. Water was evenly distributed throughout the study area. Cultivated land and other were not evenly distributed in the third-ring around. The whole area lacked large green space and water. 
Table 2. Area distribution and patch number in the center of Chengdu city.

\begin{tabular}{ccccc}
\hline Type & Area $\left.\mathbf{( k m}^{\mathbf{2}}\right)$ & The proportion of area (\%) & $\begin{array}{c}\text { Number of patches } \\
(\mathbf{n u m})\end{array}$ & $\begin{array}{c}\text { The proportion of patches } \\
\text { (\%) }\end{array}$ \\
\hline Green space & 20.69 & 10.67 & 5649 & 24.92 \\
Buildings & 107.12 & 55.24 & 5213 & 23.00 \\
Roads & 45.12 & 23.27 & 6723 & 29.67 \\
Cultivated land & 7.69 & 3.97 & 1707 & 7.53 \\
Water & 4.24 & 2.19 & 808 & 3.56 \\
Other & 9.06 & 4.66 & 2566 & 11.32 \\
Sum & 193.92 & 100.00 & 22,666 & 100.00 \\
\hline
\end{tabular}

\subsection{Analysis of Landscape Spatial Pattern Based on the Type Level}

\subsubsection{Analysis of Shape Feature of Urban Landscape}

Landscape Shape Index (LSI) reflect the degree of patch shape rules, Mean Shape Index (MSI) reflect the complexity of patch shape, Mean Patch Fractal Dimension (MPFD) reflect the complexity of patch boundary [11], and Area-Weighted Mean Shape Index (AWMSI) and Area-Weighted Mean Patch Fractal Dimension (AWMPFD) can measure the landscape space complexity and human disturbance in a certain extent [12]. These were used to analyze the shape feature of the landscape.

Table 3 showed that the value of Landscape Shape Index (LSI) of roads was a maximum (94.66), followed by buildings (92.74), this showed that the two types of the shape of patch had bad rules. The value of Landscape Shape Index (LSI) of water was a minimum (12.80); this shows that the shape of this patch was the most rules. Combined with the Mean Shape Index (MSI) and Mean Patch Fractal Dimension (MPFD), the value of the building was the largest $(1.20,1.03)$, indicated that the shape of patch and boundary was more complex. Followed by roads, other types of the shape of landscape and the complex of boundary were basically at the same level. The value of Area-Weighted Mean Shape Index (AWMSI) of roads was a maximum (13.27), followed by buildings (7.96). And the value of Area-Weighted Mean Patch Fractal Dimension (AWMPFD) of buildings was a maximum (1.26), followed by roads (1.23), indicated that compared with other types of landscape, the spatial pattern of buildings and roads was more complex, man-made interference was the largest.

\subsubsection{Analysis of the Fragmentation of Urban Landscape}

Patch Density (PD), Edge Density (ED), Mean Patch Size (MPS) and Fragmentation (FN) can indicate the degree of heterogeneity and fragmentation of landscape well [9] [13]. According to Figure 2, the value of Patch Density (PD) and Edge Density (ED) of buildings, roads and green space were significantly higher than that of cultivated land, water and other, indicated that landscape heterogeneity of buildings, roads and green space were relatively high, suffered the greatest degree of human disturbance. And the value of Mean Patch Size (MPS) of green space was a minimum (0.37) among buildings, roads and green space, and the value of Fragmentation $(\mathrm{FN})$ of green space was a maximum $\left(15.26 \times 10^{3}\right)$; this showed that the degree of the fragmentation of landscape was the highest in the study area, from a single, average whole tended to be complex, heterogeneous patches.

\subsubsection{Analysis of Assembling and Parting of Urban Landscape}

Aggregation Index (AI) and Interspersion and Juxtaposition Index (IJI) are selected to indicate the assembling and parting of landscape. According to Figure 3, the value of Aggregation Index (AI) of buildings was the highest (72.23), followed by roads (57.96), indicated that the distribution of buildings was most concentrated, and presented patch agglomeration shape distribution in a large area. In addition to other, the value of Aggregation Index (AI) of green space was the lowest (48.9), green space generally showed sporadic zonal distribution. The value of Interspersion and Juxtaposition Index (IJI) of buildings was the highest (74.12), this showed that buildings next to other types patch, and had the highest mosaicism. And because roads under the influence of human activities, and presented annular distribution, the value of Interspersion and Juxtaposition Index (IJI) was the lowest (40.40). 

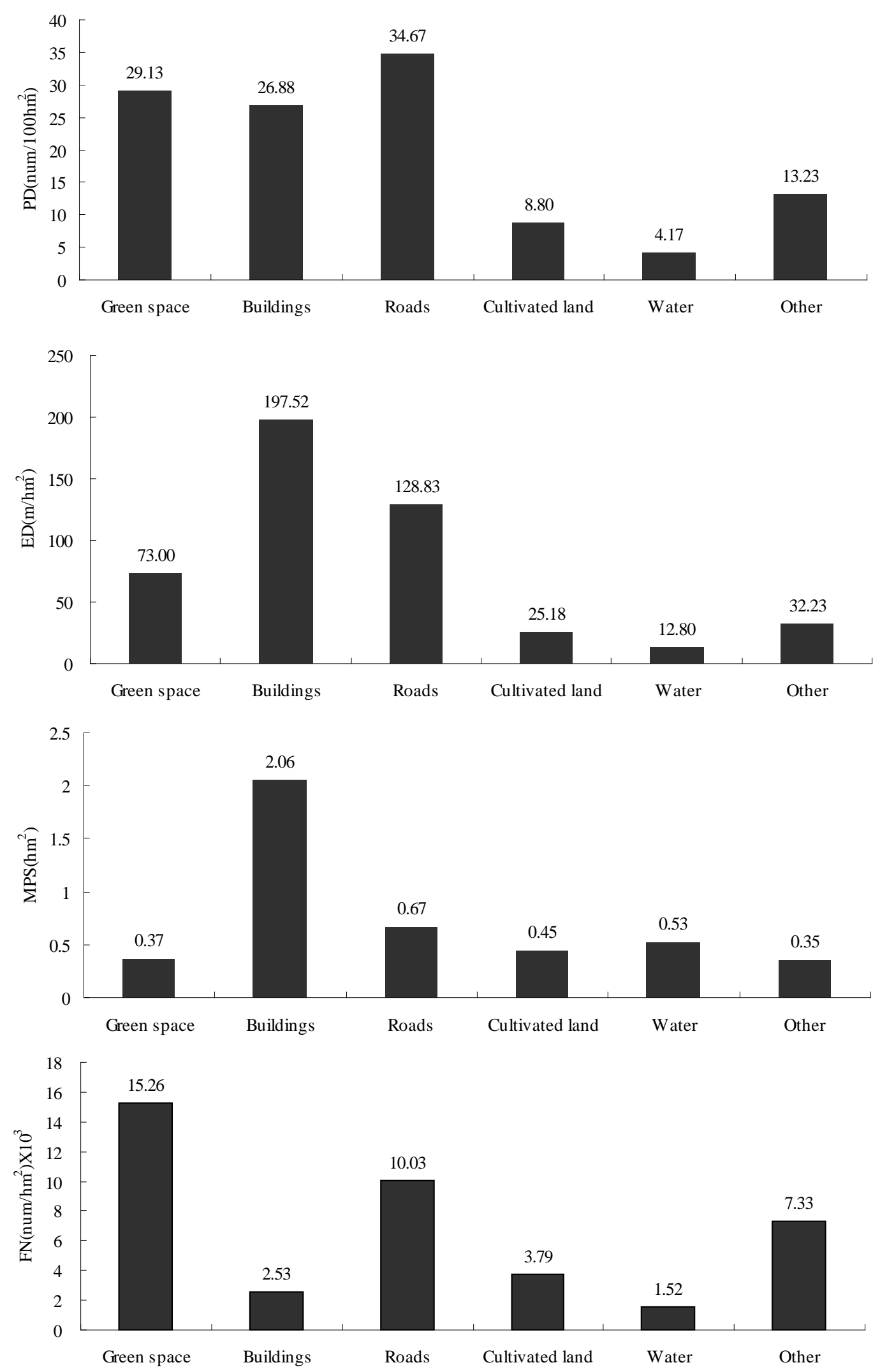

Figure 2. Fragmentation indexes change in the center of Chengdu city. 

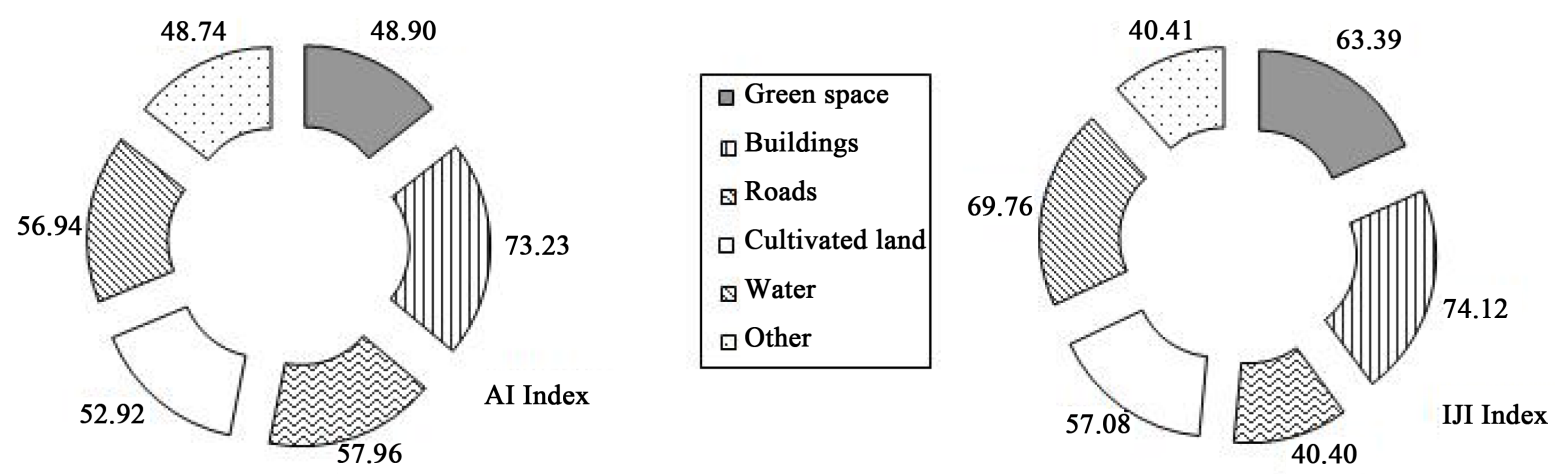

Figure 3. Assembling and parting indexes change in the center of Chengdu city.

Table 3. The shape characteristics of landscape in the center of Chengdu city.

\begin{tabular}{cccccc}
\hline Type & LSI & MSI & MPFD & AWMSI & AWMPFD \\
\hline Green space & 77.78 & 1.09 & 1.02 & 1.69 & 1.09 \\
Buildings & 92.74 & 1.20 & 1.03 & 7.96 & 1.26 \\
Roads & 94.66 & 1.12 & 1.03 & 13.27 & 1.23 \\
Cultivated land & 25.19 & 1.11 & 1.02 & 1.73 & 2.15 \\
Water & 12.80 & 1.12 & 1.02 & 1.62 & 1.13 \\
Other & 32.23 & 1.07 & 1.02 & & 1.08 \\
\hline
\end{tabular}

\subsection{Analysis of Landscape Spatial Pattern Based on the Landscape Level}

For the overall landscape pattern in the study area, Patch Density (PD) reached 116.88, and the value of Contagion Index (CONTAG) was 37.80, indicated that the study area was dense pattern and has many elements; the degree of landscape fragmentation was higher. The value of Mean Patch Fractal Dimension (MPFD) was low (1.02), indicated that human disturbance was larger. The value of Shannon's Diversity Index (SHDI) was 0.63, the value of Shannon's Evenness Index (SHEI) was 0.70, buildings and roads gathered in the second-ring road, green space and cultivated land gathered in the second-ring road to the third-ring road, it was led to the decrease of diversity, the uneven distribution of landscape area and large differences in the overall landscape. The value of Aggregation Index (AI) was 64.81, illustrated that the aggregation degree of the landscape was higher, and compact layout of the whole city.

\section{Conclusions and Discussion}

The formation of urban landscape pattern is correlated with the implementation of urban comprehensive planning. Master plan of Chengdu (2003-2020) pointed out that the construction of Chengdu is built from the natural two rivers around the city to planning annual and radial structure. This needs to absorb and undertake more transfer of people in the planning period, the problem of employment; housing and environment have become increasingly prominent. This article is based on the study of landscape pattern of Chengdu, combined with the feature of remote sensing image and the status of land use, extracted the landscape index to study landscape pattern in center of Chengdu. In order to solve the problem of ecological environment of urban planning and construction, and seek a new breakthrough for the development of the city, we get the following main conclusions and suggestions.

1) $55.24 \%$ of the total area was made up of buildings in the center of Chengdu; it was the dominant type of landscape. And green space, cultivated land and water only account for $32.62 \%$; this showed that the area of landscape types with natural elements was less and the distribution of landscape types was uneven. To effectively solve the city problem, we should make the concentric circle structure of city evolution to the belt type gradually and weigh the proportion of the impervious surface landscape and the natural landscape element to increase the patch of large green space and water. 
2) The degree of fragmentation of landscape was high, and the diversity was low in the center of Chengdu city. Due to urban planning, human disturbance of buildings, roads and green space was the most serious. Especially the patch of green space was too broken to play a role in regulating climate, reducing noise and protecting biodiversity, etc.

3) Urban landscape had obvious artifact, and lacked of connectivity between the various landscape types. The value of Mean Patch Fractal Dimension (MPFD) was 1.02 in the center of Chengdu city. The results indicated that the region has been highly artificial; naturalness and complexity were not enough, and lacked of contact between the various landscape types, in order to make the various types of urban landscape give full play to the proper ecological function, and reproduce the traditional styles and features with the two rivers surrounded and green shade everywhere of Chengdu.

\section{Acknowledgements}

The research is financed by the National Natural Science Foundation of China (31572293), the Natural Science project of the Sichuan department of education (16ZB0177), the Fundamental Research Funds of China West Normal University (14D010) and the Sichuan Research Center for Landscape and Recreation Research Project (JGYQ201407).

\section{References}

[1] Wang, M. (2016) The Development Process and the Problem of Urbanization in China. Legality Vision, 12, 296.

[2] Han, W.Q., Chang, Y., Hu, Y.M., Li, X.Z. and Bu, R.C. (2005) Research Advance in Landscape Pattern Optimization. Chinese Journal of Ecology, 12, 1487-1492.

[3] Zhang, Y., Wang, Y.N., Chen, L. and Liu, X.Y. (2014) Forest Vegetation Information Computer Automatic Extraction Based on Landsat-8. Chinese Agricultural Science Bulletin, 28, 61-66.

[4] He, X.L., Peng, P.H., Wang, Y.K., Fu, B., Chen, Y.F. and Shi, Z.D. (2014) Study on Dynamic Landscape Pattern of Greening Space in the Center of Chengdu City. Journal of West China Forestry Science, 5, 30-35.

[5] Gao, S.P., Chen, Q.B. and Xie, Y.C. (2005) The Realistic Analysis of Landscape Pattern of Urban Greening System in the Center of Chengdu. Chinese Landscape Architecture, 7, 49-52.

[6] Chen, H., Gu, L., Li, Y.Q. and Mu, C.L. (2009) Analysis on Relations between the Pattern of Urban Forests and Heat Island Effect in Chengdu. Acta Ecologica Sinica, 9, 4865-4874.

[7] Chen, W.J., Gao, X.J., Liu, R.R. and He, Z.W. (2015) An Analysis on Urban Impervious Surface and Its Relation with Thermal Environments Based on Landsat-8. Geomatics \& Spatial Information Technology, 4, 92-95.

[8] Ou, D.H., Xia, J.G., Zhang, L., Ou, X.F. and Zhao, Z. (2015) The Application of RS and GIS Techology in Meso-Scale Landscape Classification and Cartography: A Case Study in Longquanyi District of Chengdu. Chinese Journal of Ecology, 10, 2971-2982.

[9] Yang, W.R. (2015) Spatiotemporal Change and Driving Forces of Urban Landscape Pattern in Beijing. Acta Ecologica Sinica, 13, 4357-4366.

[10] Deng, J.S., Wang, K., Li, J., Xu, J.F., Shen, Z.Q. and Gao, Y.R. (2006) Impacts of Farmland Consolidation on Farmland Landscape. Chinese Journal of Applied Ecology, 1, 41-44.

[11] Loehle, C. and Wein, G. (1994) Landscape Habitat Diversity: A Multiscale Information Theory Approach. Ecological Modeling, 3-4, 311-329. http://dx.doi.org/10.1016/0304-3800(94)90068-X

[12] Zhang, J.D., Qiu, Y. and Zheng, F.Y. (2000) Quantitative Methods in Landscape Pattern Analysis. Journal of Mountain Science, 4, 346-352.

[13] Zhang, Y.X. and Guo, J.P. (2001) The Dynamic of Patch Density and Edge Density in Forested Landscape of Shanxi, China. Chinese Journal of Ecology, 1, 18-21. 